EPhemeris for CoMet TeMPeL ${ }_{2}$ IgO4 c.-In No. 3986 of the Astronomische Nachrichten M. J. Coniel gives a daily ephemeris for 'Tempel's second comet extending from January 3 to March 2, which is a continuation of the ephemeris published by him in No. $397 \mathrm{I}$ of the same journal. Although the southern declination of the comet is decreasing, its R.A. is so near to that of the sun, and the object itself is so faint, that observations will be difficult, and only possible immediately after sunset.

The comet's position on January $2 \mathrm{I}$ will be

$$
\text { R.A. }=22 \mathrm{~h} .37 \mathrm{~m} \cdot 47 \mathrm{~s} ., \text { dec. }=-16^{\circ} 19^{\prime} .
$$

Seasonal Development of Martian Canals.-A further contribution of observed phenomena, in support of his theory concerning the causes which produce the seasonal development of the canals on Mars, is published by Mr. Lowell in the January number of Popular Astronomy. The particular canal therein discussed is Brontes, which is 2440 miles in length and connects along a great circle, in nearly a north and south direction, the two important points Linus Titanum and the Propontis.

From a study of ninety drawings made during the period January-July, x903, six of which are reproduced on the plate accompanying the paper, it was seen that the visibility of the canal increased after the summer solstice in the northern hemisphere, and, further, on dividing the canal into five nearly equal sections from north to south, the section nearest the north polar cap became strengthened first, and the others followed in order of their north polar distance. This is plainly shown on the visibility "cartouches" given by Mr. Lowell, who considers the phenomena as a further proof of his theory that the visibility of a canal is due to vegetation, quickened by the water loosened at the melting of the polar snows and flowing towards the equator. The extension south of the equator is considered as a probable proof of intelligent artificial interference in the propulsion of the water.

Variable Stars and Nebulous areas in Scorpio.-An examination of thirty-three plates exposed on the large nebulous regions mentioned in previous Circulars has led Miss H. S. Leavitt to the discovery of 105 new variable stars in the constellation Scorpio.

The positions of these, for 1900 , their greatest and least observed magnitudes, and their magnitude ranges are given in No. 90 of the Harvard College Observatory Circulars.

The most striking result of this research has been the revelation of vast areas of diffused nebulous matter, so faint as to be beyond visual observation. One of these areas extends over a number of square degrees in the constellations Ophiuchus and Scorpio, and, like the Orion nebula, it attaches itself to individual stars, the principal condensation being about the quadruple star $\rho$ Ophiuchi. The region is marked by an absence of faint stars, and dark lines may be traced beyond the confines of the nebulosity as yet seen on the plates.

Report of the Natal Observatory.-The report of Mr. E. Nevill, Government astronomer of Natal, for the year 1903, gives a brief résumé of the work accomplished at the Durban Observatory during the period with which the report deals, and contains a mass of information respecting the meteorology of the colony.

The time signals have been sent out as in former years, and Borrelly's comet was observed regularly during its appearance, the orbit deduced from the observations agreeing with those obtained at other observatories.

It is proposed to utilise the tide observations made during the years $1884-8$ in order to provide the port authorities with tide-tables, but, owing to the constructional changes in the harbour during the last few years, it will be necessary to reduce the more recent observations and this will require additional computing assistance.

In former years it has been customary to issue the meteorological data compiled from the returns of the subsidiary stations once each month, but in future the returns will be published daily. Among the numerous tables given in the report there occurs, for the first time, a summary of the meteorological observations made at the Botanical Gardens, Durban, during the period $1873^{-1} 88_{3}$ NO. 1838 , voL. $7 \mathrm{I}]$ inclusive, before the institution of the Government observatory.

The Jesuit Observatory at Belen, Havana.-An interesting illustrated account of the observatory attached to the Jesuit College at Belen, Havana, has been written, in Spanish, by Father Mariano Gutiérrez, S.J., the subdirector, and contains a history of the installation of the institution in 1857 , and its proceedings since that date.

The meteorological section was first founded under the direction of Father Antonio Cabré, S.J., in the year named, but its position was not secured until the installation of Father Vines as director, in 1870 , to the memory of whom the author of the history pars a high tribute, and laments his death in 1893 as an irreparable loss.

The equipment of the observatory is fairly complete, and includes meteorological, seismological, magnetic, and astronomical instruments, most of which, including the 6-inch Cooke equatorial, are illustrated in the present volume.

\section{THE DISCOVERY OF JUPITER'S SIXTH SATELLITE.}

THE addition of a sixth satellite to the system of Jupiter marks another triumph in Prof. Perrine's employment of the modified Crossley reflector. As mentioned in a note published in "Our Astronomical Column" last week, Prof. Perrine first suspected the existence of the newly discovered body from observations made during December, 1904, but it was not until January 4 that a further observation confirmed his suspicion, and enabled him to open the new rear with the announcement of this important discovery.

The new satellite, so far as one may gather from the meagre news ret to hand, is situated at a much greater distance from its primary than any of the five previously known. The telegram announcing the discovery gave this distance, on January 4 , as $45^{\prime}$, whilst that of the outermost of the four satellites discovered by Galileo never exceeds $\mathrm{IO}^{\prime} \cdot 5$, and the fifth, the innermost of all, is not quite half the distance from Jupiter that the moon is from the earth.

Assuming, for the moment, that the above distance is the outward limit of the satellite's orbit, it should make one revolution about its primary in about half a year, whereas the time occupied by the fourth satellite is only r6.7 days; thus we see there is an immense gap between the two bodies which, according to precedent, may contain other satellites as yet undiscovered.

The recent discovery raises the number of satellites in the solar system, discovered during the past thirty years, to five, and it is worthy of note that the discovery of a satellite has usually occurred at times when a new instrument has been installed or old instruments or methods have been improved. This fact calls to mind, although beyond our thirty years' limit but still dealing with the Jovian system, that Jupiter's four moons, Io, Europa, Ganymede, and Callisto, or i., ii., iii., and iv. as they are usually designated, were the first members of the solar system to be discovered, resulting, as they did, from Galileo's first use of the telescope in January, x610.

After these, and within the past thirty years, came Deimos and Phobos, the lilliputian attendants to Mars, which were discovered by Prof. Asaph Hall at Washington in August, 1877 , and were the first fruits of the then recently mounted 26 -inch refractor of the U.S. Naval Observatory.

The fifth satellite of Jupiter was discovered by Prof. Barnard on September 9,1892 , with the nearly new giant refractor of the Lick Observatory. It is, comparatively, a minute object and can only be seen with the largest telescopes under the most favourable conditions. Its diameter can scarcely be greater than roo miles, whilst the diameters of the other four, in order of their distance from the planet, are 2400 , between 2000 and 2200 (about the size of our own moon), 3000 , and 3600 miles respectively. This object revolves between 
Io-the first satellite-and Jupiter in a period of Irh. $57 \mathrm{~m} .22 \cdot 6 \mathrm{~s}$.

Following this discovery came the addition, to an already numerous family, of the ninth satellite of Saturn, which was found by Prof. W. H. Pickering. The search was commenced in 1888 with the 13 -inch Boyden telescope of the Harvard College Observatory, but was not successful in bìinging to light any previously unknown attendant on Saturn. On the installation of the new 24-inch Bruce telescope in the clear atmosphere of Arequipa the search, which was photographic throughout, was renewed, and on examining the plates taken on August 16,17 , and 18 , ${ }_{1} 898$, Prof. Pickering was rewarded by the appearance of a short trail which apparently partook of the planet's motion among the stars, and was, therefore, to be considered as part of its system. The story of the subsequent doubts and difficulties has been too recently told (Harvard College Annals, No. 3, vol. liii.) to need re-telling here, but it may be recalled to mind that the subsequent observations showed that the satellite revolves in an orbit which is far more eccentric than that of any other satellite, or of any major planet, in the solar system, and that its motion in that orbit is opposite in direction to the orbital motions of the remaining eight of Saturn's moons. Like the fifth satellite of Jupiter, this object can only be observed visually with the largest telescopes and under the best conditions. As a matter of fact, it was not seen until its position was accurately known, and even then Profs. Barnard and H. H. Turner, using the 40-inch refractor at Yerikes Observatory, in August last, could not feel certain that they had really observed the object which had up to that time remained invisible to human eyes.

Whilst our knowledge of the most recently discovered satellite is as vet very scanty, Prof. Perrine's message tells us that on January 4 its position angle was $269^{\circ}$, and the daily rate of its apparent approach towards Jupiter was $45^{\prime \prime}$, i.e. about 100,000 miles.

The magnitude, I4, ascribed to it is one magnitude fainter than that of Barnard's fifth satellite, and this primarily suggests that the diameter may be less than that of the fifth, although a smaller reflecting power, or "albedo," may account for the relative faintness. Its distance from Jupiter on January 4 would probably be about 6 million miles. The statement that the motion was "retrograde " refers, of course, to the apparent motion in the $\mathrm{skr}$, and must not be confounded with a retrograde orbital motion similar to that followed by Phobe, Saturn's ninth satellite.

W. E. R.

\section{ATIIOSPHERIC AND OCEANIC CARBON DIOXIDE.}

THE carbonic acid of sea-water is usually supposed to be present in combination with certain bases, which constitute the alkalinity of the water, partly in the form of normal carbonate and partly in the form of bicarbonate, the total amount present being insufficient to convert the whole of the base into the bicarbonate. Thus the water of the North Atlantic has been found to contain 49 c.c. of carbonic acid gas per litre, whilst 54 c.c. would be required to convert the base completely into bicarbonate. That this view is not quite correct has been shown by Dr. A. Krogh, of Copenhagen, in a series of investigations on the carbon dioxide of the air and ocean. ${ }^{1}$

The reaction between carbonic acid and a normal carbonate to form a bicarbonate is, like so many chemical reactions, reversible, and equilibrium is established while a certain amount of the carbonic acid is still free. This free carbonic acid exerts a definite gaseous pressure, which varies with the total amount of carbon dioxide present and with the alkalinity of the water. This pressure can very readily be determined by simply shaking the water with a small volume of air and then ascertaining by direct analysis the pressure of the carbon dioxide in this air, which is, of course, equal to the pressure of that in the water, since the two have been brought into equilibrium by the shaking. This process gives excellent results both with fresh- and sea-water, and can be carried out very rapidly by the aid

1 "Meddelelser om Gronland," vol. xxvi. pp. 333, 409.

NO. 1838 , vOL. 7 I 7 of the apparatus of Haldane or Petterson and Sonden for the estimation of small quantities of carbon dioxide. As the result of a careful study of the behaviour of sea-water in this respect, it appears that a comparatively large amount of carbon dioxide may be absorbed, whilst the corresponding pressure only undergoes a very small absolute change, provided that the alkalinity remains constant. A water for example, which has the alkalinity 23 and contains 36.7 c.c. of carbon dioxide per litre, is capable of absorbing 4.3 c.c. of the gas per litre, whilst the pressure, measured as described above, only rises from 0.015 per cent. to 0.0295 per cent. of an atmosphere. This means that the air shaken up with the original water would be found to contain $r \cdot 5$ parts of carbon dioxide per 10,000, whilst after the further absorption the air similarly treated would contain 2.95 parts per 10,000.

Owing to this pressure of carbon dioxide constant interchange takes place between every water surface, whether of sea-water or of fresh-water, and the air above it, resulting in evolution from the water or absorption by it according as the pressure of carbon dioxide in the water or the air is the greater. The effect of this is that the ocean acts as a regulator on the amount of carbon dioxide in the air, tending to compensate for any deviation from the normal proportion. The pressure of carbon dioxide in the air is at present about 0.03 per cent. of an atmosphere (3 volumes per 10,000$)$, the absolute amount in the whole atmosphere being calculated as $2.4 \times 10^{12}$ tons, whilst the quantity contained in the entire mass of the sea may be taken as twentyseven times as great as this.

In order to increase the proportion of the atmospheric carbon dioxide to 0.04 per cent. it would be necessary, of course, in the first place to add one-third of the amount already present. The pressure thus attained would, however, be gradually decreased by absorption by the sea, and it follows from the author's experiments that in order to bring the ocean into equilibrium with the altered atmosphere a further addition of twice the amount originally present would be required, a total change involving the production of $5.6 \times 10^{12}$ tons of carbon dioxide! A calculation of this kind goes far to explain the constancy of composition of the atmosphere, which at first sight appears so remarkable, and to indicate the enormous changes required to produce any considerable variation in it.

The interchange of carbon dioxide between sea and air, moreover, is by no means a slow process, but takes place with remarkable rapidity. Thus a pressure difference between sea and air of only o.0or of an atmosphere, i.e. the presence in the air of an additional O.I part of carbon dioxide per 10,000 , leads to the absorption of 0.525 c.c. of this gas per square centimetre of ocean surface per year, or a total annual absorption of $3.85 \times 10^{9}$ tons.

The author considers from this point of view the effect on the composition of the atmosphere of the combustion of coal, which annually throws into the air about onethousandth of the carbon dioxide already present in it, so that, apart from any regulating action of the sea, in a. thousand years-if the coal lasted-the percentage propor. tion would be doubled, rising from 3 to 6 volumes per 10,000 , and rendering the air almost unfit for continued respiration. Before the proportion rose to 3 . I volumes per 10,000, however, the sea would be able to absorb the gas as fast as it was produced, and, owing to the large volume required to bring the ocean water into equilibrium with the air, it is probable that at the expiration of the thousand years the proportion of carbon dioxide in the air would not be more than 3.5 volumes per 10,000 .

Many other interesting questions of great importance in the economy of nature are capable of being attacked from this point of view and subjected to experimental invest $i$ gation. Such are the rate of deposition of calciun? carbonate from hard waters, the rate of solution of limestone and chalk in natural waters, the absorption of carbon dioxide by rocks and soils, \&c.

On the great question as to whether the production of carbon dioxide is on the whole greater or less than its decomposition nothing certain is known. Indications are not wanting, however, that this constituent of the atmosphere is increasing in quantity. The chief evidence to this effect is derived from the fact that over the sea the pressure of 